Article

\title{
An LC-MS/MS Method for a Comprehensive Determination of Metabolites of BTEX Anaerobic Degradation in Bacterial Cultures and Groundwater
}

\author{
Simon Godin ${ }^{1}$, Pawel Kubica ${ }^{1,2} \mathbb{1}$, Anthony Ranchou-Peyruse ${ }^{1} \mathbb{D}$, Isabelle Le Hecho ${ }^{1}$, \\ Delphine Patriarche ${ }^{3}\left[0\right.$, Guilhem Caumette ${ }^{4}$, Joanna Szpunar ${ }^{1, *(1)}$ and Ryszard Lobinski ${ }^{1}$ \\ 1 IPREM UMR 5254, Universite de Pau et des Pays de l'Adour, E2S UPPA, CNRS, Hélioparc, 64053 Pau, \\ France; simon.godin@univ-pau.fr (S.G.); pawkubic@pg.edu.pl (P.K.); \\ anthony.ranchou-peyruse@univ-pau.fr (A.R.-P.); isabelle.lehecho@univ-pau.fr (I.L.H.); \\ ryszard.lobinski@univ-pau.fr (R.L.) \\ 2 Department of Analytical Chemistry, Faculty of Chemistry, Gdansk University of Technology, \\ 11/12 Narutowicza Str, 80-233 Gdańsk, Poland \\ 3 STORENGY, Expertise Industrielle et Solutions pour l'Energie, 12 rue Raoul Nordling- CS50014, \\ 92277 Bois-Colombes CEDEX, France; delphine.patriarche@storengy.com \\ 4 TEREGA, 40, Avenue de l'Europe, CS 20522, 64010 Pau, France; guilhem.caumette@terega.fr \\ * Correspondence: joanna.szpunar@univ-pau.fr; Tel.: +33-559-40-77-55
}

Received: 28 May 2020; Accepted: 26 June 2020; Published: 29 June 2020

\begin{abstract}
BTEX (benzene, toluene, ethylbenzene, and the different xylene isomers), known for carcinogenic and neurotoxic effects, are common environmental contaminants. The first step for the development of the bioremediation technologies is the detection of intense microbial degradation in contaminated waters in the quest for the most active bacterial strains. This requires the multispecies analysis for BTEX metabolites which are considered as markers of microbial degradation. A direct (50 $\mu \mathrm{L}$ injection) HPLC-electrospray MS/MS analytical method was developed for the simultaneous analysis of 11 BTEX metabolites (o-, $m-, p$-toluic, salicylic, benzoate, benzyl, and phenyl succinic acids, 2-(1-phenylethyl)-, 2-(2-methylbenzyl), and 2-(3-methylbenzyl)-, 2-(4-methyl benzyl)-succinic acids) in bacterial cultures and ground waters down to $0.1 \mathrm{ng} / \mathrm{mL}$. The optimization of the chromatographic conditions allowed for the resolution of position isomers of toluic and methylbenzyl-succinic acids. The stability of the analytes during sample storage tested in different conditions showed the instability of some of them when stored at room temperature. The feasibility of the method was demonstrated by the detection of all the investigated metabolites in a water sample of a deep aquifer hosting natural gas storage. A model laboratory study emphasized the importance of 2-(2-methylbenzyl)-succinic acid as a marker of anaerobic microbial degradation.
\end{abstract}

Keywords: LC MS/MS; BTEX; metabolites; anaerobic bacteria; groundwater

\section{Introduction}

Aromatic hydrocarbons, such as benzene, toluene, ethylbenzene, and xylenes (aka BTEX), are recognized as environmental pollutants co-occurring at hazardous waste sites. Their chemical inertness, relatively high solubility in water, and toxicity make them common targets of the environmental monitoring [1,2]. Extensive data on the toxicology of BTEX, on their joint toxic actions (e.g., additive, less-than-additive, or greater-than-additive joint actions), as well as recommendations for exposure-based assessments of the potential impact on public health can be found elsewhere [3]. Fighting the environmental consequences of the BTEX spills, local contamination, and diffuse pollution 
is an issue of wide interest. Green technologies, such as using bacteria metabolizing BTEXs, are particularly promising.

Indeed, in the presence of bacteria, BTEX undergo natural degradation, which is accompanied by the production of different metabolites. The detection and quantification of the metabolites that are characteristic of in situ anaerobic (alkyl)benzene transformation is a definitive way to demonstrate the occurrence of the self-bioremediation of a BTEX-impacted site; it is also of paramount importance-along with the stable isotope fractionation analysis-for model laboratory studies aiming at elucidating the metabolic pathways [4]. Also, the understanding of the natural attenuation processes is a key to the development of efficient bioremediation and environmental engineering technologies [5].

In contrast to the aerobic degradation of BTEX known for a century [6,7], the capacity of certain microbial consortia to degrade BTEX in anoxic conditions has only recently been demonstrated [8,9]. The terminal electron acceptor systems include sulfate-reduction [10], nitrate-reduction [11], iron (III)-reduction [12], methanogenesis [13], or humic acids [14], but the metabolic pathways are still poorly understood. For benzene, the three main types of putative mechanisms include hydroxylation (producing phenol) [15-17], methylation (producing toluene) [18,19], or carboxylation (producing benzoic acid) [20,21]. However, there is controversy regarding the role of hydroxylation [13]; the synthesis of phenol was reported to be preferably due to benzene atmospheric oxidation during sampling rather than due to a biological origin [22,23]. Additionally, benzoic acid is a central metabolite of anaerobic degradation of many aromatic compounds and not exclusively characteristic of the BTEX degradation $[20,24]$.

Regarding the toluene biodegradation, direct hydroxylation of the methyl group [25] or hydroxylation of one of the ring carbon atoms $[26,27]$ were reported, but it is the hypothesis of a fumarate addition leading to benzylsuccinic acid that has been studied mostly [28-30]. In the case of ethylbenzene, a fumarate addition gives (1-phenylethyl)-succinic acid and this degradation pathway is strictly analogous to the path of benzylsuccinate in the case of toluene [31]. Krieger et al. [32] showed that $m$-xylene was transformed into 3-methylbenzyl-succinic acid via a mechanism that is similar to the degradation of toluene. On the other hand, metabolite analyses of $p$-xylene and $o$-xylene degradation revealed the presence of 4-methylbenzyl-succinic and 2-methylbenzyl-succinic acids, respectively $[28,33,34]$. $m-, 0-$, or $p$-Toluic acids were also detected as intermediates of the metabolic degradation of xylenes [34,35].

A successful delineation of BTEX microbial degradation metabolic pathways in the environment critically depends on the availability of suitable analytical methods, which should ideally be direct, sensitive, and quantify simultaneous several species. The existing methods are relatively scarce, often tedious to operate, and do not allow the complexity of the pathways to be addressed. The concentrations of BTEX encountered in ground waters may sometimes reach several hundreds of $\mathrm{ng} / \mathrm{mL}$ (for individual species), whereas the concentrations of their secondary metabolites that result from bacterial activity are an order of magnitude lower. Benzyl-succinic and methylbenzyl-succinic were directly determined by LC- electrospray MS/MS down to $0.3 \mathrm{ng} / \mathrm{mL}$ [36] or by GC-MS after solid-phase extraction (SPE) and in-vial derivatization down to $0.1 \mathrm{ng} / \mathrm{mL}$ [37]. The combination of SPE with LC MS/MS allowed the detection limits for $o-, m-, p$-toluate, and benzyl- and ethylbenzyl-succinate, down to $0.01 \mathrm{ng} / \mathrm{mL}$ (for a $100-\mathrm{mL}$ sample) [38].

The objective of this work was to develop a direct HPLC-MS/MS method for the simultaneous analysis of 11 BTEX metabolites in environmental water samples, including all three methylbenzyl derivatives of succinic acid, which are of particular interest as degradation products of xylenes but-so far-have not been included in the published protocols. The method has been tested for the analysis of ground water containing traces amount of BTEX, as well as the analysis of anaerobic bacterial cultures degrading BTEX. A study of the stability of the analytes stored in different conditions in a ground water matrix was carried out to elucidate possible degradation phenomena. 


\section{Materials and Methods}

\subsection{Standards and Procedures}

Reagents and standards. LC-MS grade acetonitrile and acetic acid were purchased from Sigma-Aldrich (Saint-Quentin-Fallavier, France). Ultrapure water (18 M $\Omega . \mathrm{cm})$ was obtained from a direct Q 3 UV Milli-Q system (Millipore, Bedford, MA). The standards of benzoic acid, o-toluic acid, $m$-toluic acid, $p$-toluic acid, salicylic acid, phenyl-succinic acid, and benzyl-succinic acid were supplied by Sigma-Aldrich. The 2-(1-phenylethyl)-succinic acid and 2-(2-methylbenzyl)-succinic acid standards were obtained from TOSLab (Ekaterinburg, Russia) and those of 2-(3-methylbenzyl)-succinic acid and 2-(4-methylbenzyl)-succinic acid from Asinex (ASINEX-REAG, Moscow, Russia).

\subsection{Samples}

Water samples. The formation water sample was collected from a monitoring well of a $853 \mathrm{~m}$ deep gas storage aquifer ( 93 bars, $36^{\circ} \mathrm{C}$ ), a layer from the lower Cretaceous, located in the Paris Basin, as described by [39]. Two aliquots of ground water from this site hosting natural gas (mainly methane and traces of BTEX) were sampled into glass vials containing $0.1 \%$ of formic acid with no head-space left. The aliquots were stored at $-20{ }^{\circ} \mathrm{C}$ prior to analysis.

Bacterial cultures. Microcosms experiments issued from bacterial matter collected with formation waters of the same deep aquifer were carried out, as described previously [40]. For the analytical study, microcosms were prepared with anoxic synthetic water mimicking the aquifer water composition (3.48 g/L NaCl, $0.06 \mathrm{~g} / \mathrm{L} \mathrm{CaCl}_{2}, 0.14 \mathrm{~g} / \mathrm{L} \mathrm{MgCl}_{2} \cdot 6 \mathrm{H}_{2} \mathrm{O}, 1 \mathrm{~g} / \mathrm{L} \mathrm{Na} \mathrm{SO}_{4}, 0.5 \mathrm{~g} / \mathrm{L} \mathrm{NH} \mathrm{Nl}_{4}, 0.3 \mathrm{~g} / \mathrm{L} \mathrm{KH}_{2} \mathrm{PO}_{4}$ ， and $\left.0.3 \mathrm{~g} / \mathrm{L} \mathrm{K}_{2} \mathrm{HPO}_{4}\right)$. Culture medium and solutions were sterilized by autoclaving at $110{ }^{\circ} \mathrm{C}$ for $30 \mathrm{~min}$. and flushed under $\mathrm{CO}_{2} / \mathrm{N}_{2}$ atmosphere (20/80) prior to the addition of carbonate solution $\left(1.1254 \mathrm{~g} / \mathrm{L} \mathrm{NaHCO}, 0.0384 \mathrm{~g} / \mathrm{L} \mathrm{KHCO}_{3}, 0.0343 \mathrm{~g} / \mathrm{L} \mathrm{Na} \mathrm{CO}_{3}\right.$ ), filtered vitamins [41], $\mathrm{FeCl}_{2} .4 \mathrm{H}_{2} \mathrm{O}$ solution $(0.168 \mathrm{~g} / \mathrm{L})$, and cysteine solution $(1 \mathrm{~g} / \mathrm{L}) . \mathrm{pH}$ was adjusted to 7.0 . The synthetic water was distributed among several penicillin flasks that were sealed with butyl rubber stoppers to maintain anoxic conditions. 10\% inoculum and BTEX (final concentration $10 \mathrm{mg} / \mathrm{L}$ each) were finally added in each flask, as previously described [40]. The incubations were carried out under static conditions at $37^{\circ} \mathrm{C}$ in the dark. BTEX concentrations were monitored in liquid samples $(0.3 \mathrm{~mL})$ collected with syringes through the stoppers by solid-phase microextraction flame ionization detection SPME-GC-FID, as described previously [40].

\subsection{Instrumentation}

For the chromatographic method optimization, an Acquity UPLC system (Waters), including a binary solvent pump, a cooled autosampler, and a column oven, was used. The detector was a XevoTQ (quadrupole-T-wave-quadrupole) MS with an orthogonal Z-spray-electrospray interface (Waters). Separations (optimized conditions) were carried out using an Acquity UPLC BEH $\mathrm{C}_{18}$ column, $150 \mathrm{~mm} \times 2.1 \mathrm{~mm} \times 1.7 \mu \mathrm{m}$, Waters, Milford, MA, USA) with a matching Vanguard BEH C181.7 $\mu \mathrm{m}$ precolumn. For the stability study, the same column was used, but the chromatographic system used was an ultimate 3000 RSLC system (ThermoFisher Scientific, Dreieich, Germany), and the detection was ensured by a Q Exactive Plus (ThermoFisher Scientific, Dreieich, Germany) high resolution mass spectrometer that was fitted with an IonMax source and an HESI II probe. An acetonitrile-water 1:1 $(v / v)$ solution was used for rinsing the syringe and external cleaning of the autosampler needle.

\subsection{Procedures}

Initial sample preparation procedure. The samples were filtered through $0.2 \mu \mathrm{m}(13 \mathrm{~mm})$ syringe filter, GHP Acrodisc (Interchim, France). 4-fluorobenzoic acid ( $\left.\alpha-{ }^{13} \mathrm{C}-2,3,5,6-\mathrm{d}_{4}\right)$ was added at $20 \mathrm{ng} / \mathrm{mL}$ as an internal standard.

Study of the stability of BTEX metabolites over sample storage in different conditions. Waters from two deep gas storage aquifers were acidified by the addition of formic acid up to $0.1 \%$ (v/v) 
and pooled together in equal amount directly after sampling. The mixture was then spiked with standard stock solutions of 10 BTEX metabolites in order to reach concentrations of $2 \mu \mathrm{g} / \mathrm{L}$ for benzyl, 2-(1-phenylethyl)-, 2-(2-methylbenzyl), and 2-(3-methylbenzyl)-, 2-(4-methyl benzyl)-succinic acids, $4 \mu \mathrm{g} / \mathrm{L}$ for phenyl succinic acid, $50 \mu \mathrm{g} / \mathrm{L}$ for o-toluic acid and salicylic acid, $60 \mu \mathrm{g} / \mathrm{L}$ for m-toluic acid, and $80 \mu \mathrm{g} / \mathrm{L}$ for p-toluic acid (benzoate was excluded from the stability study). Afterwards, the obtained solution was divided into $90 \mathrm{HPLC}$ vials each containing $1 \mathrm{~mL}$ of solution, 30 of them were then placed at room temperature in the dark, 30 were placed at $4{ }^{\circ} \mathrm{C}$ in a fridge, and 30 were placed in a freezer at $-20^{\circ} \mathrm{C}$. Over a period of 24 weeks, two vials were analysed from each storing condition at the following points: week 0 (the day the solution was prepared), week 1 , week 2 , week 3 , week 4 , week 8 , week 12 , week 16 , and week 24 .

Measurement conditions. A $50 \mu \mathrm{L}$ aliquot was analyzed by HPLC-MS/MS. The mobile phase was composed by mixing $0.2 \% \mathrm{CH}_{3} \mathrm{COOH}(\mathrm{A})$ and $0.2 \% \mathrm{CH}_{3} \mathrm{COOH}$ in acetonitrile (B). The elution gradient was: $0 \mathrm{~min}$. (13\% B), $1.3 \mathrm{~min}$. (13\% B), $9 \mathrm{~min}$. $(28 \% \mathrm{~B})$, and $13 \mathrm{~min} .(80 \% \mathrm{~B})$. The column was equilibrated for $5 \mathrm{~min}$. The flow rate was $0.45 \mathrm{~mL} / \mathrm{min}$, the column temperature was $45{ }^{\circ} \mathrm{C}$ and the autosampler temperature was $5{ }^{\circ} \mathrm{C}$. MS/MS data acquisition was performed in the negative ionization mode $\left(\mathrm{ESI}_{n e g}\right)$ under the MRM conditions that are listed in Table 1. For the stability study, the mass spectrometer was operated in PRM mode. The source conditions were, as follows: ion transfer tube temperature $-350{ }^{\circ} \mathrm{C}$, auxiliary gas heater $-350{ }^{\circ} \mathrm{C}$, sheath gas, auxiliary gas, and sweep gas flow rates $-50,20$, and 1 , respectively (arbitrary units), spray voltage $-3 \mathrm{kV}$. The resolution for MS/MS scans was set to 35,000 and the isolation window for precursor isolation was $0.4 \mathrm{~m} / \mathrm{z}$. An AGC target of 105 was used and a maximum injection time of $100 \mathrm{~ms}$ was set. The higher energy collisional dissociation (HCD) collision energy was set to 50 for toluic acids, 10 for benzoate, 20 for salicylic acid, 40 for methylbenzyl, phenylethyl and benzyl succinic acid derivatives, and 20 for phenyl succinic acid. Independent scanning segments were created for each peak or group of peaks in order to maximize the scan rates.

Table 1. MS/MS Measurement Conditions.

\begin{tabular}{cccccc}
\hline Name & Formula & Mass & Ion Transition & Cone (V) & Collision (V) \\
\hline $\begin{array}{c}\text { o-toluic acid } \\
\text { m-toluic acid } \\
\text { p-toluic acid }\end{array}$ & $\mathrm{C}_{8} \mathrm{H}_{8} \mathrm{O}_{2}$ & 136.15 & $135.0 \rightarrow 91.0$ & 24 & 10 \\
\hline benzoate & & & & 26 & 12 \\
\hline salicylic acid & $\mathrm{C}_{7} \mathrm{H}_{6} \mathrm{O}_{2}$ & 122.12 & $120.9 \rightarrow 77.0$ & 22 & 10 \\
\hline $\begin{array}{c}\text { 2-(2-methylbenzyl)-succinic acid } \\
\text { 2-(3-methylbenzyl)-succinic acid }\end{array}$ & $\mathrm{C}_{7} \mathrm{H}_{6} \mathrm{O}_{3}$ & 138.12 & $135.9 \rightarrow 93$ & 25 & 16 \\
\hline 2-(4-methylbenzyl)-succinic acid & $\mathrm{C}_{12} \mathrm{H}_{14} \mathrm{O}_{4}$ & 222.23 & $221.1 \rightarrow 177.1$ & 25 & 14 \\
\hline 2-(1-phenylethyl)-succinic acid & $\mathrm{C}_{12} \mathrm{H}_{14} \mathrm{O}_{4}$ & 222.23 & $221.1 \rightarrow 177.1$ & 28 & 14 \\
\hline Phenyl-succinic acid & $\mathrm{C}_{10} \mathrm{H}_{10} \mathrm{O}_{4}$ & 194.18 & $193.0 \rightarrow 149.0$ & 14 & 15 \\
\hline Benzyl-succinic acid & $\mathrm{C}_{11} \mathrm{H}_{12} \mathrm{O}_{4}$ & 208.21 & $207.0 \rightarrow 163.1$ & 24 & 14 \\
\hline iso-4FBA (IS) & $\mathrm{C}_{6} \mathrm{D}_{4}{ }^{13} \mathrm{CO}_{2} \mathrm{HF}$ & 145.13 & $144.0 \rightarrow 99.1$ & 20 & 14 \\
\hline
\end{tabular}

Calibration. The calibration curves were constructed by plotting peak area for five concentrations: $0.5,1,10,50$, and $100 \mathrm{ng} / \mathrm{mL}$.

Data processing. The Masslynx software (Waters, Milford, MA) was used to process data for the chromatographic method optimization. TraceFinder 4.1 (ThermoFisher Scientific, Waltham, MA, USA) was used for the stability study. A dedicated compound database containing retention times as well as precursor and fragments masses for all analytes was created in the software. Mass tolerance was set to 5 ppm and the peak detection algorithm was ICIS with the following parameters: area and peak noise factor were set to 5 and 10, respectively, baseline window was set to 60, minimum peak height was 3 
$(\mathrm{S} / \mathrm{N})$, and minimum peak width was set to 3 (minor adjustments were applied to some analytes to favor a good integration). For calibration, a threshold value of 0.99 for $\mathrm{R}^{2}$ was set.

\section{Results and Discussion}

Although many metabolites are formed during BTEX biodegradation, only some can be considered as indicative molecules of complete hydrocarbon mineralization and should be chosen for the monitoring [42]. On this basis benzoate, $o_{-}^{-}, \mathrm{m}^{-}$, and $p$-toluic acids, 2-(2-methylbenzyl)-, 2-(3-methylbenzyl)-, 2-(4-methylbenzyl)-, and 2-(1-phenylethyl)-succinic acids and phenyl- and benzyl-succinic acids were selected. Salicylic acid is a compound that is commonly used as a biomarker for the aerobic degradation of polycyclic aromatic hydrocarbons [43-46]. Morash and collaborators were also able to detect salicylic acid during the anaerobic degradation of toluene and benzoate in a sulfate-reducing bacterial culture [33]. However, we found the interest in this compound limited because of ubiquitous occurrence, which does not allow for discrimination between samples contaminated with BTEX, or not. This is probably due to the fact that the sampled deep aquifer water could contain microorganisms from surface environments (soil, water, tubing) in the absence of an adapted cleaning of the well. Many soil bacteria are able to produce salicylic acid [47]. This has been especially highlighted in iron-limiting environments. Therefore, we consider salicylic acid as a biomarker for the anaerobic degradation of toluene, which is non-relevant in the context of our environments.

\subsection{Chromatographic Optimization}

The separation of complex mixtures is problematic, especially when dealing with compounds that are position isomers (differing by the position of methyl group in the structure), such as toluic acids (peaks 1-3, upper panels in Figure 1a-c) or methylbenzyl-succinic acids along with 2-(1-phenylethyl)-succinic acid (peaks 4-7, bottom panels in Figure 1a-c). These separations are critical, as all of the position isomers fragment by losing carboxyl group producing non-specific transition in the MRM mode and relatively high background noise. The separation depends on the type (stationary phase and length) of the column used, and on the concentration of the acid modifier (acetic acid).

Choice of the column. For the method development, different columns (all supplied by Waters) were used: UPLC HSS T3 (high strength silica, $50 \times 2.1 \mathrm{~mm} 1.7 \mu \mathrm{m}$ ) and two UPLC BEH (ethylene bridge hybrid C18, $50 \times 2.1 \mathrm{~mm} 1.7 \mu \mathrm{m}$ and $150 \times 2.1 \mathrm{~mm} 1.7 \mu \mathrm{m})$. In the preliminary studies the 50-mm columns were discarded due to the fact that no conditions could be found to resolve the methylbenzyl-succinic and the toluic acids. 2-(3-methylbenzyl)- and 2-(4-methylbenzyl)-succinic acid were eluted, as one peak and m-toluic acid and p-toluic acid were coeluted at $80 \%$ of their height in the best of the conditions tested. Therefore, a 15-cm column, BEH C18 $150 \times 2.1 \mathrm{~mm} 1.7 \mu \mathrm{m}$, was chosen.

Choice of the elution conditions. The separation of position isomers required the gradient elution to be slow and partially isocratic in order to increase the degree of resolution of methylbenzyl-succinic acids. However, an increase in the amount of aqueous phase at the beginning of the gradient did not result in better separations, but in wider and less intense peaks. The optimal parameters were obtained for the initial organic concentration in the range from $10-18 \%$. A mixture of methanol and acetonitrile was tested (8:2 ACN:MeOH and 5:5 ACN:MeOH) as well, but the separation was worse in comparison to those that were obtained with acetonitrile only. 
a)
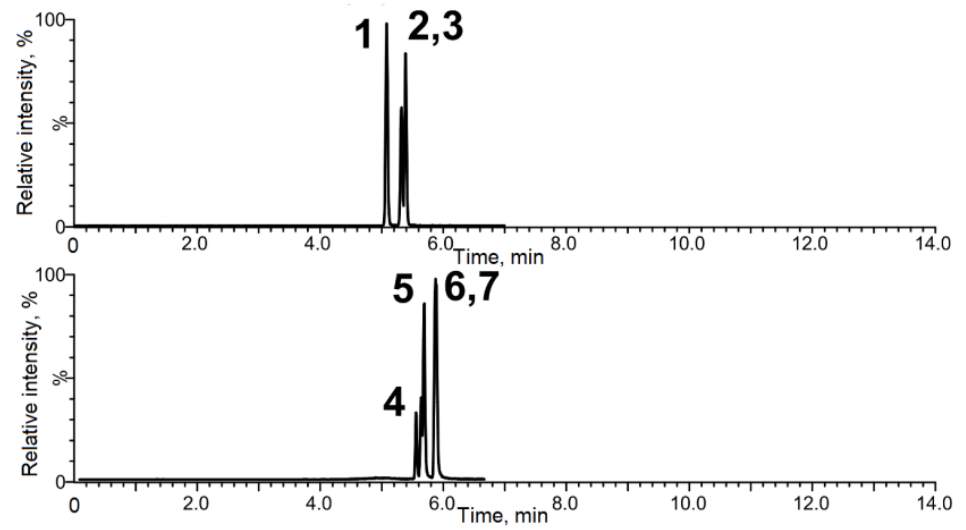

b)
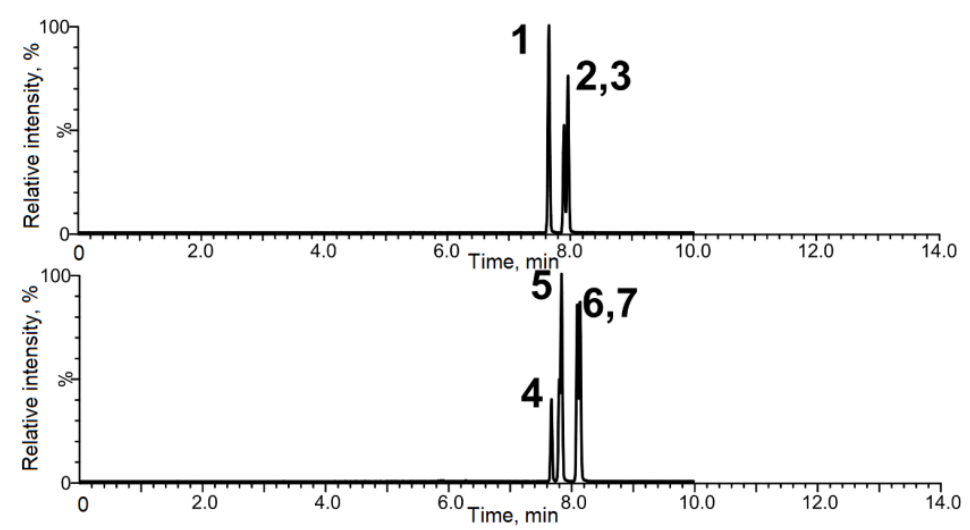

c)

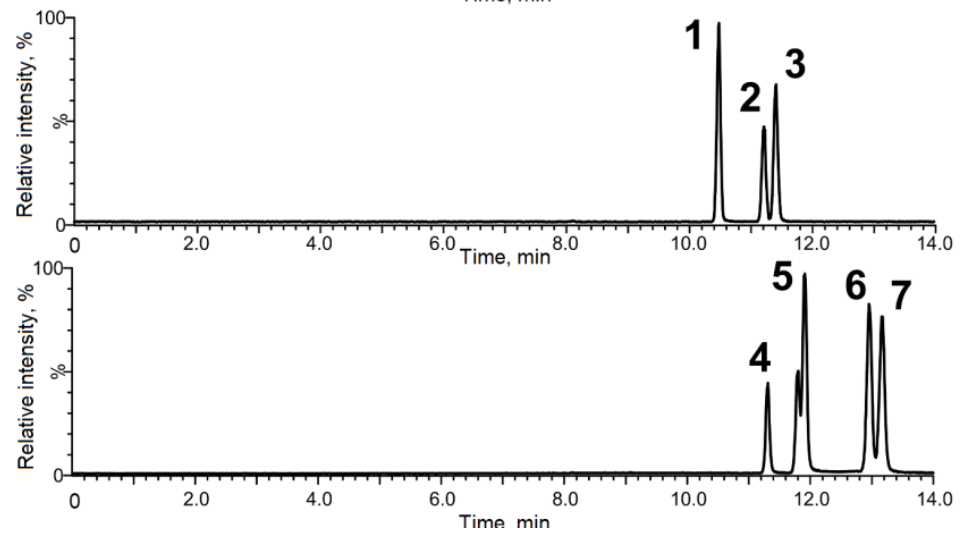

Figure 1. Optimization of the HPLC separation of metabolite position isomers of the toluic and methylbenzylsuccinic acids. $1-o$-toluic acid, $2-m$-toluic acid, $3-p$-toluic acid, 4-2-(1-phenylethyl)-succinic acid, 5-2-(2-methylbenzyl)succinic acid, 6-2-(3-methylbenzyl)succinic acid, and 7-2-(2-methylbenzyl)succinic acid). Acetic acid concentration in the mobile phase: (a) $0.05 \%$, (b) $0.1 \%$, and (c) $0.2 \%$. Column BEH C18 $(50 \times 2.1 \mathrm{~mm} \times 1.7 \mu \mathrm{m})$.

Aqueous and organic components of the mobile phase were acidified with formic acid and acetic acid. The addition of formic acid, even in small amounts $(0.01 \%)$, resulted in the signal suppression. Therefore, the use of acetic acid was privileged. Figure 1 shows the effect of the acetic acid concentration on the separation of the two groups (toluic and succinic acids, upper and bottom panels in Figure 1, respectively) of position isomers. At concentrations of $0.01 \%, 0.05 \%$, and $0.1 \%$, the peaks were split due to the fact that $\mathrm{pH}$ of the mobile phase was above and/or close to the $\mathrm{pKa}$ of analytes. The increase of acetic acid up to $0.2 \%$ in organic and aqueous ( $\mathrm{A}$ and $\mathrm{B}$ ) eluent components resulted in narrower peaks that did not split ( $\mathrm{pH}$ was under the $\mathrm{pKa}$ ); however, it extended the retention times of all the analytes (Figure 1c). This eluent concentration was used for further work.

The temperature of the column compartment was increased to $45^{\circ} \mathrm{C}$ to shorten the total chromatographic run time. Despite this, the first peak only appeared after $8 \mathrm{~min}$. Higher temperatures: 
50,55 , and $60^{\circ} \mathrm{C}$ had no significant influence on the retention times. The manufacturer allows for temperatures up to $80{ }^{\circ} \mathrm{C}$, but values higher than $60^{\circ} \mathrm{C}$ were not checked because of $(i)$ the risk of degradation of analytes and (ii) the risk of the stationary phase deterioration in the presence of acetic acid. Therefore, the optimum temperature was set to $45^{\circ} \mathrm{C}$.

\subsection{Validation of the Method}

The calibration curves for each of 11 metabolites were established and used to evaluate the analytes concentrations in real samples. They were linear in the whole concentration range tested (up to $100 \mathrm{ng} / \mathrm{mL}$ ) with the linearity coefficients exceeding 0.99 and limits of detection at the $0.1 \mathrm{ng} / \mathrm{mL}$ level. Figure 2 shows a chromatogram at the $1 \mathrm{ng} / \mathrm{mL}$ level for a mixture of standards. It shows a good separation efficiency and sensitivity of the method developed.

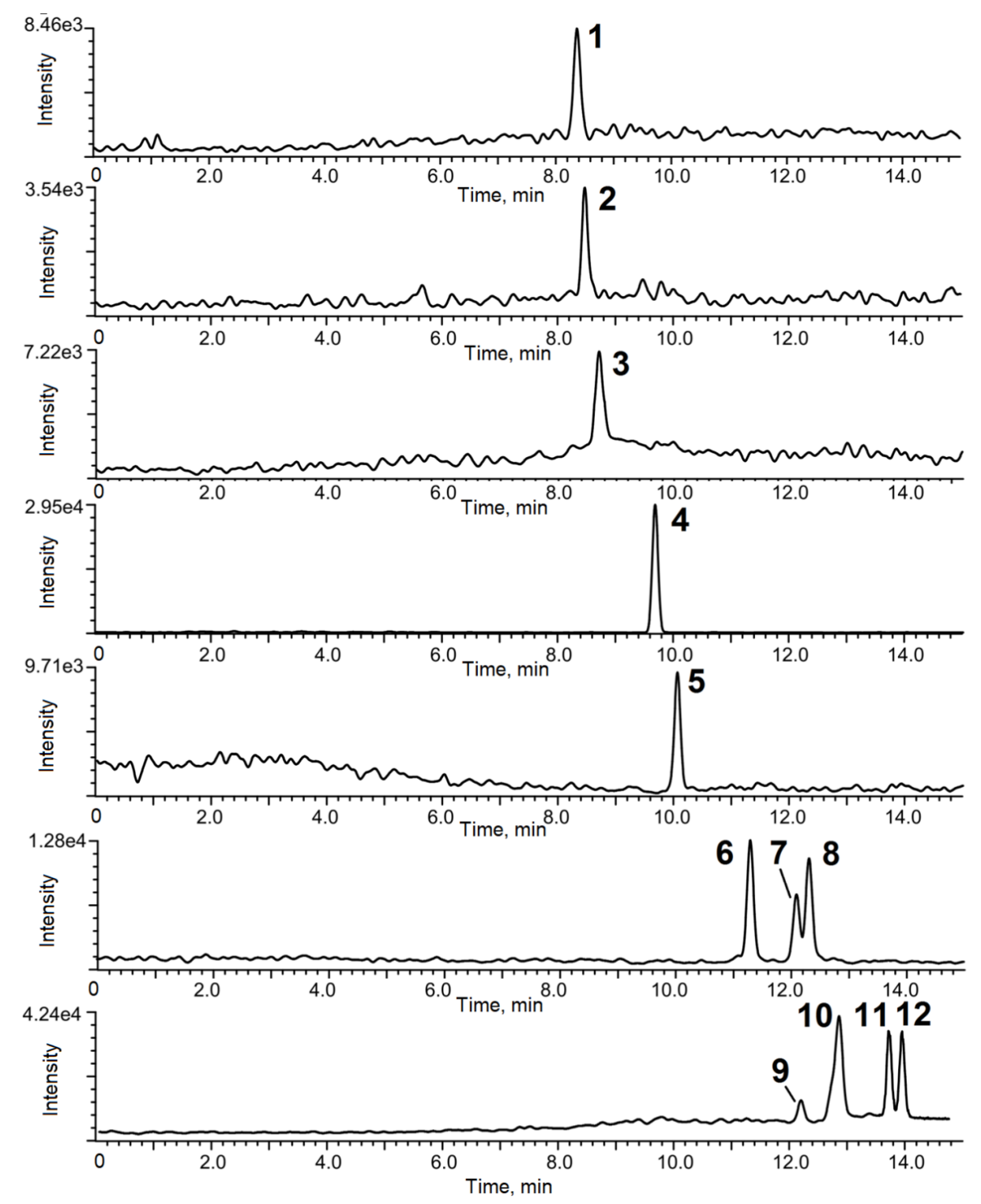

Figure 2. Chromatogram of metabolite standards ( $1 \mathrm{ng} / \mathrm{mL}$, except for IS at $10 \mathrm{ng} / \mathrm{mL})$. 1—salicylic acid, 2-phenylsuccinic acid, 3-benzoic acid, 4-4-fluorobenroic acid C13-D' (IS), 5-benzylsuccinic acid, 6-o-toluic acid, 7-m-toluic acid, 8-p-toluic acid, 9-2-(1-phenylethyl)-succinic acid, 10-2-(2-methylbenzyl)-succinic acid, 11-2-(3-methylbenzyl)-succinic acid, and 12-2-(4-methylbenzyl) -succinic acid. 
The method has been validated by analysing a blank water sample spiked with the metabolites at three different levels $(2,5$, and $25 \mathrm{ng} / \mathrm{mL})$. Recoveries higher than $90 \%$ have been obtained for all of the compounds studied, as shown in Table 2.

Table 2. Method validation.

\begin{tabular}{|c|c|c|c|}
\hline Compound & Added, (ng/mL) & Found $\pm S D,(n g / m L)$ & $\%$ of the Expected Value \\
\hline \multirow{3}{*}{ benzoic acid } & 2 & $2.18 \pm 0.07$ & 109 \\
\hline & 5 & $5.25 \pm 0.28$ & 105 \\
\hline & 25 & $23.50 \pm 0.55$ & 94 \\
\hline \multirow{3}{*}{$o$-toluic acid } & 2 & $2.18 \pm 0.14$ & 109 \\
\hline & 5 & $4.97 \pm 0.11$ & 99 \\
\hline & 25 & $23.14 \pm 1.06$ & 93 \\
\hline \multirow{3}{*}{$m$-toluic acid } & 2 & $1.86 \pm 0.09$ & 93 \\
\hline & 5 & $4.90 \pm 0.63$ & 98 \\
\hline & 25 & $23.97 \pm 0.89$ & 96 \\
\hline \multirow{3}{*}{$p$-toluic acid } & 2 & $2.16 \pm 0.08$ & 108 \\
\hline & 5 & $4.80 \pm 0.20$ & 96 \\
\hline & 25 & $26.02 \pm 0.95$ & 104 \\
\hline \multirow{4}{*}{ Salicylic acid } & 2 & $1.99 \pm 0.07$ & 99 \\
\hline & 5 & $5.21 \pm 0.09$ & 104 \\
\hline & 25 & $26.18 \pm 0.70$ & 105 \\
\hline & 2 & $1.80 \pm 0.02$ & 90 \\
\hline \multirow[t]{2}{*}{ phenylsuccinic acid } & 5 & $4.69 \pm 0.16$ & 94 \\
\hline & 25 & $23.59 \pm 1.03$ & 94 \\
\hline & 2 & $1.91 \pm 0.09$ & 96 \\
\hline \multirow[t]{3}{*}{ benzylsuccinic acid } & 5 & $5.51 \pm 0.19$ & 110 \\
\hline & 25 & $24.28 \pm 0.97$ & 97 \\
\hline & 2 & $2.10 \pm 0.03$ & 105 \\
\hline \multirow[t]{3}{*}{ 2-(1-phenylethyl) succinic acid } & 5 & $5.02 \pm 0.08$ & 100 \\
\hline & 25 & $25.61 \pm 1.42$ & 102 \\
\hline & 2 & $1.72 \pm 0.24$ & 86 \\
\hline \multirow[t]{3}{*}{ 2-(2-methylbenzyl) succinic acid } & 5 & $4.84 \pm 0.06$ & 97 \\
\hline & 25 & $25.04 \pm 1.65$ & 100 \\
\hline & 2 & $1.81 \pm 0.19$ & 90 \\
\hline \multirow[t]{3}{*}{ 2-(3-methylbenzyl) succinic acid } & 5 & $4.69 \pm 0.23$ & 94 \\
\hline & 25 & $23.60 \pm 1.13$ & 94 \\
\hline & 2 & $1.82 \pm 0.11$ & 91 \\
\hline \multirow[t]{2}{*}{ 2-(4-methylbenzyl) succinic acid } & 5 & $4.35 \pm 0.25$ & 87 \\
\hline & 25 & $23.66 \pm 1.15$ & 95 \\
\hline
\end{tabular}

\subsection{Stability Study of BTEX Metabolites during Sample Storage}

Figure 3 shows the evolution of the concentration for each of the metabolites during sample storage over a period of 24 weeks in different conditions. These data indicate that there is no substantial difference in metabolites stability between a storage at 4 or $-20{ }^{\circ} \mathrm{C}$, except in the case of salicylic acid, which is only stable for a short term at $20{ }^{\circ} \mathrm{C}$, whereas it is totally degraded within a week at room temperature or $4^{\circ} \mathrm{C}$. Other metabolites studied exhibit a rather good stability when stored at 4 or $-20{ }^{\circ} \mathrm{C}$; however, storage at room temperature shows an important degradation of toluic acids after four weeks, while degradation occurs to a lesser extent in this condition for benzyl, phenyl, 2-(1-phenylethyl), 2-(3-methylbenzyl), and 2-(4-methylbenzyl) succinic acids from week 12. All in all, these data show that storing sample at $-20{ }^{\circ} \mathrm{C}$ is a suitable condition if the samples are analyzed within a month after sampling. 

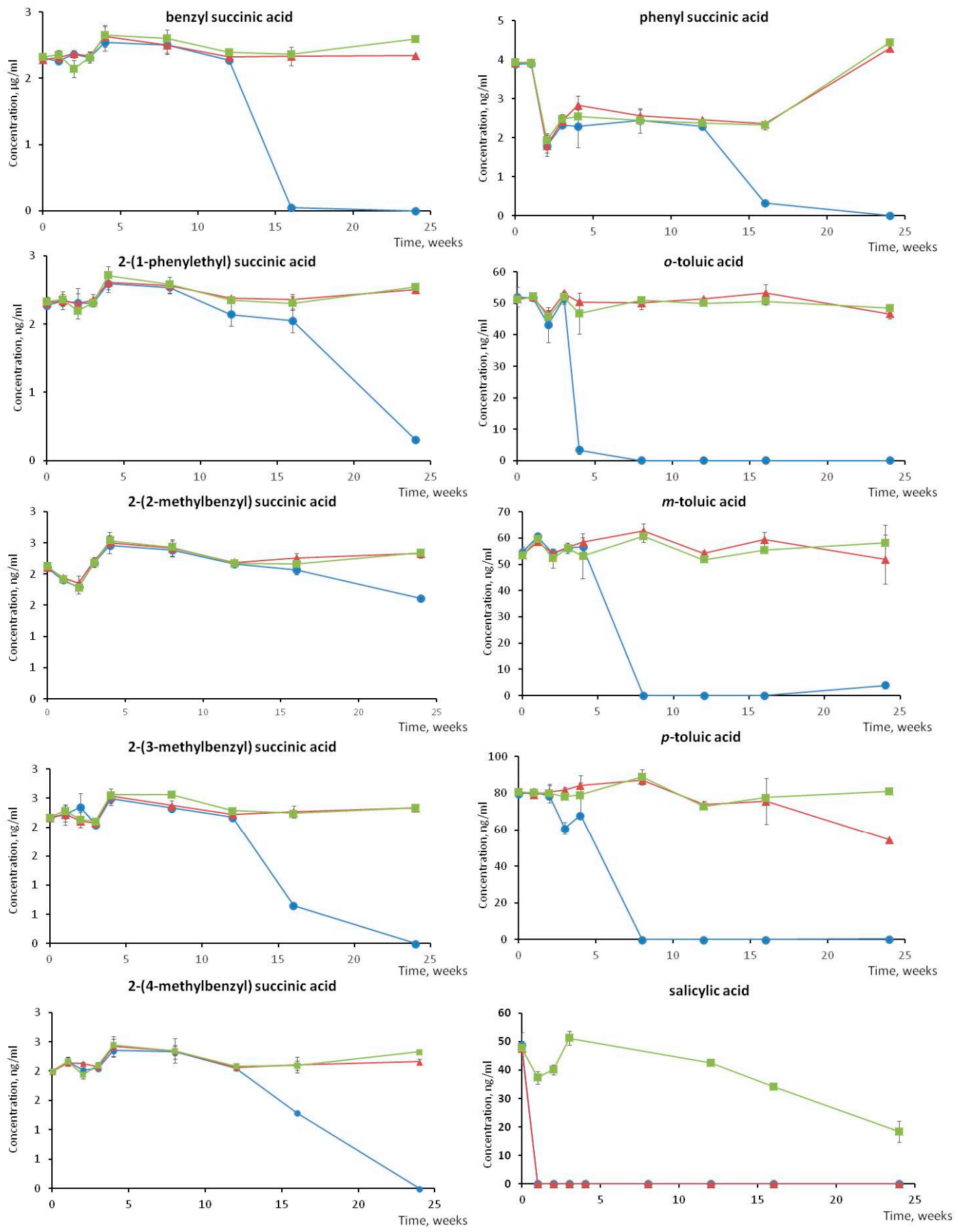

Figure 3. Evolution of the concentration of benzene, toluene, ethylbenzene, and andxylenes (BTEX) metabolites during sample storage at room temperature (blue curve), $4{ }^{\circ} \mathrm{C}$ (red curve) and $-20{ }^{\circ} \mathrm{C}$ (green curve) over 24 weeks (deep gas storage aquifer water spiked with known initial concentration for the purpose of a stability study).

\subsection{Analysis of Ground Water}

Figure 4 shows a chromatogram of a ground water sample from a BTEX impacted site. The blanks were zoomed to demonstrate the absence of the contamination or false positives (Figure 5) All eleven metabolites investigated were detected, which proves that the method developed can be used to follow the anaerobic biodegradation of BTEX. Indeed, no other metabolism than anaerobic toluene biodegradation can produce benzylsuccinic acid [48]. The addition of fumarate to the toluene is due to a particular fumarate-adding enzyme: benzylsuccinate synthase [2,49-51]. It is reasonable to assume 
that other enzymes close to benzylsuccinate synthase may catalyse the degradation of other BTEX of which the metabolites were found: (2-(1-phenylethyl)-succinic acid (ethylbenzene degradation), 2-(2-methylbenzyl-succinic acid (o-xylene degradation), 2-(3 -methylbenzyl)-succinic acid ( $p$-xylene degradation), and 2-(4-methylbenzyl)-succinic acid ( $m$-xylene degradation). $m-, 0-$, and $p$-Toluic acids, which appear later in the metabolic pathways [28,33,34], have also been detected. Table 3 provides the concentrations found. This is the first report of a comprehensive detection BTEX metabolites in a water sample of a deep aquifer hosting natural gas storage, which indicates a strong microbial activity. Six of the detected species are below the $1 \mathrm{ng} / \mathrm{mL}$ level, which would have escaped most of the literature protocols.

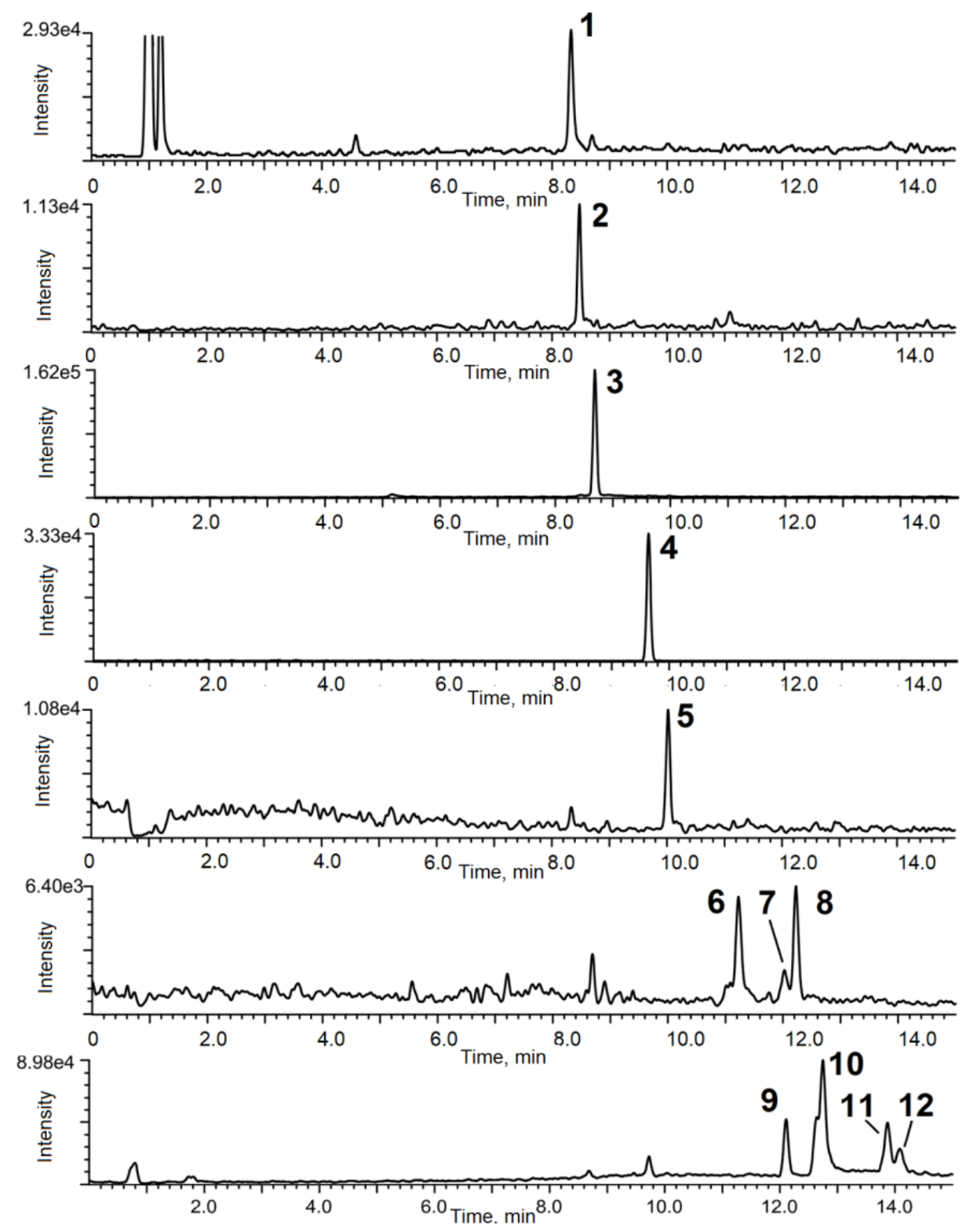

Figure 4. Chromatograms of a deep gas storage aquifer water sample. 1-salicylic acid, 2-phenyl-succinic acid, 3-benzoic acid, 4-4-fluorobenzoic acid C13-D' (IS), 5-benzyl-succinic acid, 6-o-toluic acid, 7-m-toluic acid, 8-p-toluic acid, 9-2-(1-phenylethyl)succinic acid, 10-2-(2-methylbenzyl)-succinic acid, 11-2-(3-methylbenzyl)-succinic acid, 12-2-(4-methylbenzyl)succinic acid. Note the difference in the y-axis scales which were chosen for the maximum zoom of the chromatogram. 

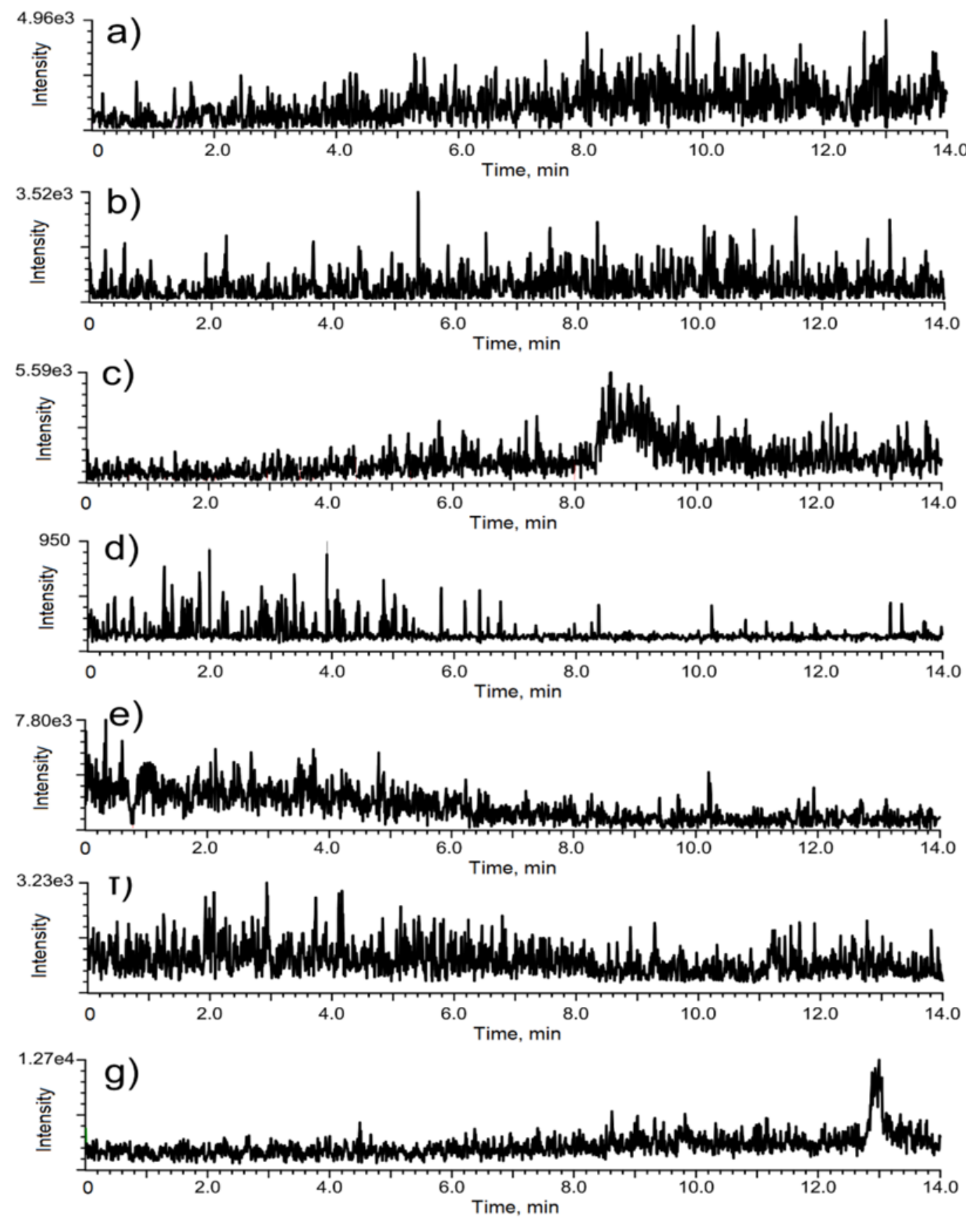

Figure 5. Chromatograms of a blank corresponding to the deep gas storage aquifer water sample (cf. Figure 4. measured for $\mathrm{m} / \mathrm{z}$ (a) $135.9 \rightarrow 93.0$, (b) $193.0 \rightarrow 149.0$, (c) $120.9 \rightarrow 77.0$, (d) $144.0 \rightarrow 99.1$, (e) $207.0 \rightarrow 163.1$, (f) $135.0 \rightarrow 91.0$, (g) $221.1 \rightarrow 177.1$. 
Table 3. Concentrations of BTEX Metabolites Found in the Ground Water Sample from Deep Gas Storage Aquifer.

\begin{tabular}{cc}
\hline Compound & ng/mL \\
\hline benzoate & $85.3 \pm 3.8$ \\
$o$-toluic acid & $0.8 \pm 0.1$ \\
$m$-toluic acid & $0.3 \pm 0.1$ \\
-toluic acid & $0.8 \pm 0.1$ \\
salicylic acid & $3.9 \pm 0.3$ \\
phenyl succinic acid & $3.8 \pm 0.4$ \\
benzyl succinic acid & $1.7 \pm 0.3$ \\
2-(1-phenyl-ethyl) succinic acid & $0.5 \pm 0.1$ \\
2-(2-methyl-benzyl) succinic acid & $0.5 \pm 0.1$ \\
2-(3- methyl-benzyl) succinic acid & $0.2 \pm 0.04$ \\
2-(4- methyl-benzyl) succinic acid & $1.0 \pm 0.2$ \\
\hline
\end{tabular}

\subsection{Analysis of Bacterial Cultures}

The analysed sample was a bacterial culture spiked with a mixture of benzene, toluene, and $o_{-}, p-$, and $m$-xylenes at $t=0$, after one year and two years. The analysis was carried out after three years (one year after the last BTEX addition). Only benzene was not degraded. Figure 6 shows that two metabolites: benzoate and 2-(2-methylbenzyl)-succinic acid, were detected. Benzoate is ubiquitous in biological processes of the degradation of aromatic compounds (PAH, lignin, flavonoids, quinone, aromatic amino acids) [52]. 2-(2-methyl-benzyl) succinic acid is a metabolite in the pathway of $o$-xylene degradation: $o$-xylene $\geq 2$-(2-methylbenzyl) succinic acid $\geq 2$-methylphenylitaconic acid $\geq 2$-methylbenzoylsuccinic acid $\geq 3$-o-toluyl propionic acid $\geq 0$-toluic acid. In this bacterial culture, $o$-xylene was completely degraded 263 days after the complete degradation of toluene and $p$-xylene. Therefore, it is likely that their metabolites benzylsuccinic and 2-(4-methylbenzyl)-succinic acids were consumed by the bacterial community. This experiment proved the usefulness of 2-(2-methyl-benzyl)-succinic acid as a marker of BTEX degradation, especially that $o$-toluic acid could not be detected. 
a)
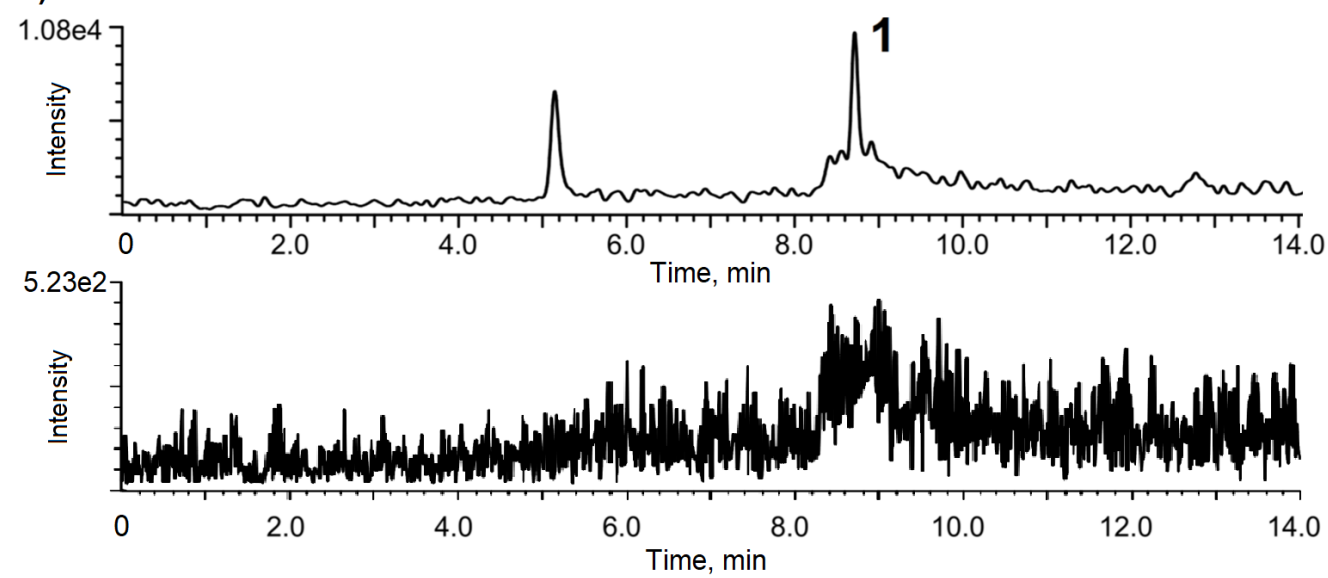

b)
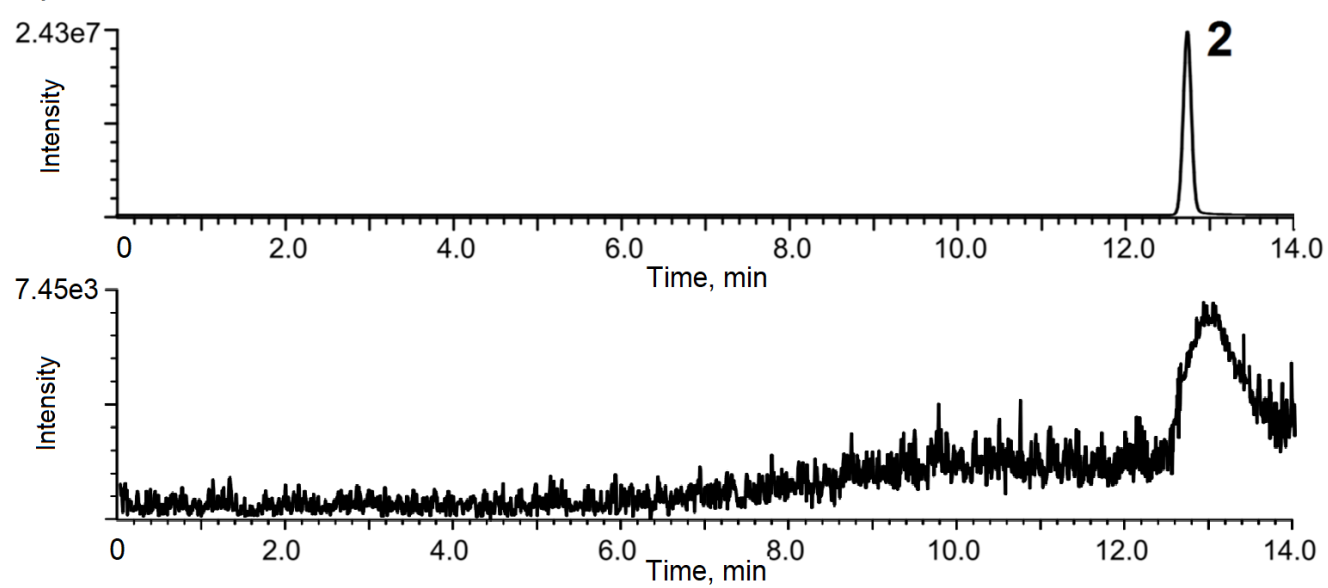

Figure 6. Chromatogram of biological culture sample: (a) benzoic acid (1) (b) 2-(2-methylbenzyl)-succinic acid (2); sample and blank chromatograms are shown on upper and lower panels, respectively. Note the difference in the y-axis scales which were chosen for the maximum zoom of the chromatogram.

\section{Conclusions}

In summary, the developed method offers unmatched performance being direct (avoiding sample preparation), sensitive ( $\mathrm{DL}<0.1 \mathrm{ng} / \mathrm{mL}$ which is by far less than most of the methods reported elsewhere) and allowing the simultaneous analysis for the highest number of BTEX metabolites ever reported. For the first time, all of the expected metabolites were detected in a deep aquifer hosting natural gas storage -the study is, to our best knowledge, the first to provide data on the stability of BTEX which can be critical when the time between the sampling and analysis is long; 2-(2-methylbenzyl)-succinic acid was found to be a marker of anaerobic microbial degradation.

The HPLC-MS/MS method developed allows for the simultaneous determination of 11 BTEX metabolites at concentration levels compatible with those present in real-field samples. The analysis is direct and straightforward: no preconcentration and/or tedious sample preparations is necessary. The detection of BTEX metabolites in ground waters sampled in a deep aquifer hosting a natural gas storage is proof of the occurrence of microbial degradation, which is essential for the natural attenuation of the BTEX compounds. Being multi-species, the method facilitates handling the complexity of the biodegradation pathways. It allows not only the monitoring of environments impacted by BTEX and chances for their natural attenuation, but it also offers an analytical support tool for microbiological studies aimed at selecting and/or engineering bacterial cultures that are capable of BTEX decontamination. The study is the first report of a comprehensive detection BTEX metabolites in 
a water sample of a deep aquifer hosting natural gas storage. Its figures of merit can be improved by using the latest generation of instrumentation (triple quad or Orbitrap operating in the PRM mode) and faster separation HPLC columns. An online preconcentration step also seems possible if necessary to lower the limits of detection.

Author Contributions: Conceptualization: J.S., A.R.-P., I.L.H. and R.L., supervision: J.S., methodology and analysis: S.G. and P.K., investigation: A.R.-P. and J.S., resources and project administration: G.C., D.P. and I.L.H.; original draft preparation: J.S., final review of the manuscript: everybody. All authors have read and agreed to the published version of the manuscript.

Funding: The funding of the FT MS platform by the EQUIPEX ANR-11-EQPX-0027 MARSS project is acknowledged.

Conflicts of Interest: The authors declare no conflict of interest.

\section{References}

1. Van Agteren, M.H.; Keuning, S.; Janssen, D. Handbook on Biodegradation and Biological Treatment of Hazardous Organic Compounds; Kluwer Academic Publishers: Berlin/Heidelberg, Germany, 1998.

2. Winderl, C.; Schaefer, S.; Lueders, T. Detection of anaerobic toluene and hydrocarbon degraders in contaminated aquifers using benzylsuccinate synthase (bssA) genes as a functional marker. Environ. Microbiol. 2007, 9, 1035-1046. [CrossRef]

3. U.S. Department of Health and Human Services. Public Health Service, Interaction profile for: Benzene, toluene, ethylbenzene, and xylenes (BTEX). Agency Toxic Subst. Dis. Regist. 2004. Available online: https://www.atsdr.cdc.gov/interactionprofiles/ip05.html (accessed on 28 May 2020).

4. Bombach, P.; Richnow, H.H.; Kästner, M.; Fischer, A. Current approaches for the assessment of in situ biodegradation. Appl. Microbiol. Biotechnol. 2010, 86, 839-852. [CrossRef]

5. Agrawal, A.; Gieg, L.M. In situ detection of anaerobic alkane metabolites in subsurface environments. Front. Microbiol. 2013, 4, 140. [CrossRef]

6. Gibson, D.T. Initial stages in microbial degradation of aromatic hydrocarbons. J. Am. Oil Chem. Soc. 1970, $47,337$.

7. Hopper, D.J. Incorporation of O-18 water in formation of para-hydroxybenzyl alcohol by para-cresol methylhydroxylase from Pseudomonas-putida. Biochem. J. 1978, 175, 345-347. [CrossRef]

8. Kuhn, E.P.; Colberg, P.J.; Schnoor, J.L.; Wanner, O.; Zehnder, A.J.P.; Schwarzenbach, R.P. Microbial transformations of substituted benzenes during infiltration of river water to groundwater-Laboratory column studies. Environ. Sci. Technol. 1985, 19, 961-968. [CrossRef]

9. Wilson, B.H.; Smith, G.B.; Rees, J.F. Biotransformations of selected alkylbenzenes and halogenated aliphatic-hydrocarbons in methanogenic aquifer material-A microcosm study. Environ. Sci. Technol. 1986, 20, 997-1002. [CrossRef]

10. Muller, S.; Vogt, C.; Laube, M.; Harms, H.; Kleinsteuber, S. Community dynamics within a bacterial consortium during growth on toluene under sulfate-reducing conditions. FEMS Microbiol. Ecol. 2009, 70, 586-596. [CrossRef]

11. Van der Zaan, B.M.; Saia, F.T.; Stams, A.J.M.; Plugge, C.M.; de Vos, W.M.; Smidt, H.; Langenhoff, A.A.M.; Gerritse, J. Anaerobic benzene degradation under denitrifying conditions: Peptococcaceae as dominant benzene degraders and evidence for a syntrophic process. Environ. Microbiol. 2012, 14, 1171-1181. [CrossRef] [PubMed]

12. Anderson, R.T.; Rooney-Varga, J.N.; Gaw, C.V.; Lovley, D.R. Anaerobic benzene oxidation in the fe (III) reduction zone of petroleum-contaminated aquifers. Environ. Sci. Technol. 1998, 32, 1222-1229. [CrossRef]

13. Masumoto, H.; Kurisu, F.; Kasuga, I.; Tourlousse, D.M.; Furumai, H. Complete mineralization of benzene by a methanogenic enrichment culture and effect of putative metabolites on the degradation. Chemosphere 2012, 86, 822-828. [CrossRef]

14. Cervantes, F.J.; Mancilla, A.R.; Toro, E.E.R.; Alpuche-Solís, A.G.; Lorenzana, L.M. Anaerobic degradation of benzene by enriched consortia with humic acids as terminal electron acceptors. J. Hazard. Mater. 2011, 195, 201-207. [CrossRef] [PubMed]

15. Grbic-Galic, D. O-demethylation, dehydroxylation, ring-reduction and cleavage of aromatic substrates by enterobacteriaceae under anaerobic conditions. J. Appl. Bacteriol. 1986, 61, 491-497. [CrossRef] [PubMed] 
16. Grbic-Galic, D.; Vogel, T.M. Transformation of toluene and benzene by mixed methanogenic cultures. Appl. Environ. Microbiol. 1987, 53, 254-260. [CrossRef]

17. Weiner, J.M.; Lovley, D.R. Rapid benzene degradation in methanogenic sediments from a petroleum-contaminated aquifer. Appl. Environ. Microbiol. 1998, 64, 1937-1939. [CrossRef]

18. Coates, J.D.; Chakraborty, R.; McInerney, M.J. Anaerobic benzene biodegradation-A new era. Res. Microbiol. 2002, 153, 621-628. [CrossRef]

19. Ulrich, A.C.; Beller, H.R.; Edwards, E.A. Metabolites detected during biodegradation of 13C6-benzene in nitrate-reducing and methanogenic enrichment cultures. Environ. Sci. Technol. 2005, 39, 6681-6691. [CrossRef]

20. Boll, M. Dearomatizing benzene ring reductases. J. Mol. Microbiol. Biotechnol. 2005, 10, 132-142. [CrossRef]

21. Holmes, D.E.; Risso, C.; Smith, J.A.; Lovley, D.R. Anaerobic oxidation of benzene by the hyperthermophilic archaeon ferroglobus placidus. Appl. Environ. Microbiol. 2011, 77, 5926-5933. [CrossRef]

22. Abu Laban, N.; Selesi, D.; Jobelius, C.; Meckenstock, R.U. Anaerobic benzene degradation by gram-positive sulfate-reducing bacteria. FEMS Microbiol. Ecol. 2009, 68, 300-311. [CrossRef]

23. Kunapuli, U.; Griebler, C.; Beller, H.R.; Meckenstock, R.U. Identification of intermediates formed during anaerobic benzene degradation by an iron-reducing enrichment culture. Environ. Microbiol. 2008, 10, 1703-1712. [CrossRef] [PubMed]

24. Harwood, C.S.; Burchhardt, G.; Herrmann, H.; Fuchs, G. Anaerobic metabolism of aromatic compounds via the benzoyl-CoA pathway. FEMS Microbiol. Rev. 1999, 22, 439-458. [CrossRef]

25. Frazer, A.C.; Coschigano, P.W.; Young, L.Y. Toluene metabolism under anaerobic conditions: A review. Anaerobe 1995, 1, 293-303. [CrossRef]

26. Langenhoff, A.A.M.; Brouwers-Ceiler, D.L.; Engelberting, J.H.L.; Quist, J.J.; Wolkenfelt, J.G.P.N.; Zehnder, A.J.B.; Schraa, G. Microbial reduction of manganese coupled to toluene oxidation. FEMS Microbiol. Ecol. 1995, 22, 119-127. [CrossRef]

27. Langenhoff, A.A.M.; Nijenhuis, I.; Tan, N.C.G.; Briglia, M.; Zehnder, A.J.B.; Schraa, G. Characterisation of a manganese-reducing, toluene-degrading enrichment culture. FEMS Microbiol. Ecol. 1997, 24, 113-125. [CrossRef]

28. Beller, H.R.; Spormann, A.M. Benzylsuccinate formation as a means of anaerobic toluene activation by sulfate-reducing strain prtol1. Appl. Environ. Microbiol. 1997, 63, 3729-3731. [CrossRef]

29. Biegert, T.; Fuchs, G.; Heider, J. Evidence that anaerobic oxidation of toluene in the denitrifying bacterium Thauera aromatica is initiated by formation of benzylsuccinate from toluene and fumarate. Eur. J. Biochem. FEBS 1996, 238, 661-668. [CrossRef]

30. Leuthner, B.; Heider, J. Anaerobic toluene catabolism of Thauera aromatica: The bbs operon codes for enzymes of $\beta$ oxidation of the intermediate benzylsuccinate. J. Bacteriol. 2000, 182, 272-277. [CrossRef]

31. Philipp, B.; Schink, B. Different strategies in anaerobic biodegradation of aromatic compounds: Nitrate reducers versus strict anaerobes. Environ. Microbiol. Rep. 2012, 4, 469-478. [CrossRef]

32. Krieger, C.J.; Beller, H.R.; Reinhard, M.; Spormann, A.M. Initial reactions in anaerobic oxidation of m-xylene by the denitrifying bacterium Azoarcus sp strain T. J. Bacteriol. 1999, 181, 6403-6410. [CrossRef]

33. Morasch, B.; Meckenstock, R.U. Anaerobic degradation of p-xylene by a sulfate-reducing enrichment culture. Curr. Microbiol. 2005, 51, 127-130. [CrossRef] [PubMed]

34. 34 Morasch, B.; Schink, B.; Tebbe, C.C.; Meckenstock, R.U. CDegradation of o-xylene and m-xylene by a novel sulfate-reducer belonging to the genus Desulfotomaculum. Arch. Microbiol. 2004, 181, 407-417. [CrossRef] [PubMed]

35. Raymond, R.L.; Jamison, V.W.; Hudson, J.O. Microbial Hydrocarbon Co-oxidation I. Oxidation of mono- and dicyclic hydrocarbons by soil isolates of the genus Nocardia. Appl. Microbiol. 1967, 15, 357-865.

36. Beller, H.R. Analysis of benzylsuccinates in groundwater by liquid chromatography tandem mass spectrometry and its use for monitoring in situ BTEX biodegradetion. Environ. Sci. Technol. 2002, 36, 2724-2728. [CrossRef] [PubMed]

37. Lotte Ask Reitzel, A.L.; Bjerg, P.L. Quantitative determination of toluene, ethylbenzene and xylene degradation products in contaminated groundwater by solid-phase extraction and in-vial derivatization. Int. J. Environ. Anal. Chem. 2005, 85, 1075-1087. [CrossRef] 
38. Alumbaugh, R.E.; Gieg, L.M.; Field, J.A. Determination of alkylbenzene metabolites in groundwater by solid-phase extraction and liquid chromatography-tandem mass spectrometry. J. Chromatogr. A 2004, 1042, 89-97. [CrossRef] [PubMed]

39. Basso, O.; Lascourrèges, J.F.; Jarry, M.; Magot, M. The effect of cleaning and disinfecting the sampling well on the microbial communities of deep subsurface water samples. Environ. Microbiol. 2005, 7, 13-21. [CrossRef]

40. Berlendis, S.; Lascourreges, J.F.; Schraauwers, B.; Sivadon, P.; Magoy, M. Anaerobic biodegradation of BTEX by original bacterial communities from an underground gas storage aquifer. Environ. Sci. Technol. 2010, 44, 3621-3628. [CrossRef]

41. Pfennig, N.; Widdel, F.; Trüper, H.G. The dissimilatory sulfate-reducing bacteria. Prokaryotes 1981, 1, 926-940.

42. Beller, H.R. Metabolic indicators for detecting in situ anaerobic alkylbenzene degradation. Biodegradation 2000, 11, 125-139. [CrossRef]

43. Heitzer, A.; Malachowsky, K.; Thonnard, J.E.; Bienkowski, P.R.; White, D.C.; Sayler, G.S. Optical biosensor for environmental on-line monitoring of naphthalene and salicylate bioavailability with an immobilized bioluminescent catabolic reporter bacterium. Appl. Environ. Microbiol. 1994, 60, 1487-1494. [CrossRef] [PubMed]

44. Eaton, R.W.; Chapman, P.J. Bacterial metabolism of naphthalene: construction and use of recombinant bacteria to study ring cleavage of 1, 2-dihydroxynaphthalene and subsequent reactions. J. Bacteriol. 1992, 174, 7542-7554. [CrossRef]

45. Lyu, Y.; Zheng, W.; Zheng, T.; Tian, Y. Biodegradation of polycyclic aromatic hydrocarbons by Novosphingobium pentaromativorans US6-1. PLoS ONE 2014, 9, e101438. [CrossRef] [PubMed]

46. Tomás-Gallardo, L.; Gómez-Álvarez, H.; Santero, E.; Floriano, B. Combination of degradation pathways for naphthalene utilization in R hodococcus sp. strain TFB. Microb. Biotechnol. 2013, 7, 100. [CrossRef] [PubMed]

47. Bakker, P.A.H.M.; Ran, L.X.; Mercado-Blanco, J. Rhizobacterial salicylate production provokes headaches! Plant. Soil 2014, 382, 1. [CrossRef]

48. Von Netzer, F.; Pilloni, G.; Kleindienst, S.; Krüger, M.; Knittel, K.; Gründger, F.; Lueders, T. Enhanced gene detection assays for fumarate-adding enzymes allow uncovering of anaerobic hydrocarbon degraders in terrestrial and marine systems. Appl. Environ. Microbiol. 2013, 79, 543-552. [CrossRef]

49. Acosta-González, A.; Rosselli, R.; Marquï, S. Diversity of benzylsuccinate synthase-like (bssA) genes in hydrocarbon-polluted marine sediments suggests substrate-dependent clustering. Appl. Environ. Microbiol. 2013, 79, 3667-3676. [CrossRef]

50. Funk, M.A.; Judd, E.T.; Marsh, E.N.G.; Elliott, S.J.; Drennan, C.L. Structures of benzylsuccinate synthase elucidate roles of accessory subunits in glycyl radical enzyme activation and activity. PNAS 2014, 111, 10161-10166. [CrossRef]

51. Lueders, T.; von Netzer, F. Primers: Functional Genes for Anaerobic Hydrocarbon Degrading Microbes; Springer Protocols Handbooks: Berlin/Heidelberg, Germany, 2014. [CrossRef]

52. Carmona, M.; Zamarro, M.T.; Blázquez, B.; Durante-Rodríguez, G.; Juárez, J.F.; Valderrama, J.A.; Barragán, M.J.L.; García, J.L.; Díaz, E. Anaerobic catabolism of aromatic compounds: a genetic and genomic view. Microbiol. Mol. Biol. Rev. 2009, 73, 71. [CrossRef]

(C) 2020 by the authors. Licensee MDPI, Basel, Switzerland. This article is an open access article distributed under the terms and conditions of the Creative Commons Attribution (CC BY) license (http://creativecommons.org/licenses/by/4.0/). 